\title{
Do New Drugs Meet the Expectations in the Treatment of Idiopathic Pulmonary Fibrosis?
}

\author{
Oğuzhan Okutan, Ömer Ayten
}

Department of Chest Diseases, Gülhane Military Medical Academy Haydarpaşa Training Hospital, İstanbul, Turkey

Idiopathic pulmonary fibrosis (IPF) is a disease for which the definition has been known for approximately a century. The classifications of interstitial pulmonary diseases begun in the 1960s and took final shape in the ATS/ERS joint guideline that was published in 2013 (1).

The approaches related to IPF have significantly changed, particularly after the 2011 guideline (2). While a requirement for surgical biopsy emerged for the diagnosis of most cases before the publication of the latest guideline, this approach changed after the publication of the guideline. Moreover, developments in radiological imaging techniques have provided convenience.

With the introduction of the "usual interstitial pneumonia" pattern radiologically, the requirement for biopsy disappeared in a considerable number of cases that were suspected of IPF. However, the importance and necessity of a multidisciplinary approach in diagnosing IPF was displayed in this context.

The new diagnosis and treatment guideline also made important changes in the applications of therapies and in the diagnostic approaches. In the guideline, explicit views were stated regarding corticosteroids or combinations with corticosteroids, which had been previously widely used, and it was emphasized that they must not be used. Instead, an approach emphasizing on particular alternatives apart from medical treatment was displayed.

Soon after the publication of the guideline, two active agents were approved for the indication of IPF by the U.S. Food and Drug Administration (FDA): pirfenidone, which has been used for treating IPF in the Far East, North America, and some European countries since the beginning of the 2000s, and nintedanib, which is a new molecule used for treating IPF. These two drugs are expected to be used in our country after obtaining the approval of FDA.

Idiopathic pulmonary fibrosis has been more frequently encountered because of reasons such as longer life spans, developments in diagnostic technologies, and more widespread factors that can cause the disease (although its etiology is unknown, environmental factors and smoking are considered to be important factors). Pirfenidone and nintedanib offer exciting benefits such as the 5-year survival at the rate of $20 \%$ and improvements in the progression and functional parameters of the disease, for which we cannot apply a curative treatment to stop deterioration.

Studies conducted on the indications for these two anti-fibrotic drugs included patients with mild and moderate IPF, and the changes in forced vital capacity (FVC) were evaluated over a 52-week period. The results of the Assessment of Pirfenidone to Confirm Efficacy and Safety in Idiopathic Pulmonary Fibrosis (ASCEND) and Clinical Studies Assessing Pirfenidone in Idiopathic Pulmonary Fibrosis: Research of Efficacy and Safety Outcomes (CAPACITY) studies $(3,4)$, which were performed for pirfenidone, and also the results of INPULSIS-1 and INPULSIS-2 studies, which were performed for nintedanib (5), are highly important.

In the ASCEND and CAPACITY studies, FVC change was considered as the primary endpoint. In the ASCEND study, a $116-\mathrm{mL}$ gain was found in patients taking pirfenidone in terms of FVC change com- 
pared with those taking the placebo (3). On the other hand, in the CAPACITY study, it was observed that pirfenidone reduced all-cause mortality and IPF-induced mortality (4).

In the INPULSIS- 1 and 2 studies, FVC was the primary endpoint and compared with the control group, the difference per year was found to be 125.3 and $93.7 \mathrm{~mL}$, respectively (5). While no difference was observed at the time of the first exacerbation in INPULSIS-1, there was a difference at the time of first exacerbation in INPULSIS-2. In terms of possible side effects that can develop because of medication, the most common ones are diarrhea and nausea. It was found that the effects of nintedanib on all-cause mortality and mortality induced by respiratory factors were statistically insignificant $(6,7)$.

Severe cases were not included in these studies. The course of IPF differs. Some forms of IPF are slowly or rapidly progressive and some involve a changing course with exacerbations. The reason for the occurrence of these differences is not yet known. It can be suggested that the responses to a treatment given to patients with different courses of disease can differ. In the case of obtaining different responses to a treatment, the results of the studies would be controversial. We have no data on this issue. Exacerbations are important for the course of the disease. In the INPULSIS-2 study, Richeldi et al. (5) emphasized that nintedanib delayed the time of the first exacerbation.

Both drugs have undesired effects at a non-negligible rate. Gastrointestinal side effects are the most common ones. However, photosensitivity associated with pirfenidone can seriously affect patients in sunny and hot places, even if preventive measures are taken.

With regard to treatment costs, albeit there are differences in the prices of the two active agents in different countries, the treatment cost per month is around USD 9000. This fact should be properly evaluated with our expectations from treatment.

Single or combined drug therapy in the treatment of IPF will be discussed more frequently in the forthcoming days. In our country, the drugs, including these two agents, can still be supplied with foreign drug procedures. Although the indication studies were conducted on patients with mild and moderate disease, there are no limitations on the prescription in this respect. Accurate presentation of the expectations at the beginning of treatment and the performance of monitorization procedures and other recommendations apart from medical therapy will help inform and increase our expectations from treatment.

In a disease without a curative treatment, the introduction of new treatment modalities that slow down the progress of the disease and that have effects on functional parameters is promising. In the upcoming days, we will see the results of studies on combined therapies. Cases should be shared in multi-center studies for gaining more experience. In this issue of our journal, the first results of a center for patients that were given pirfenidone for the treatment of IPF were published in the "letter to editor" section (8). The publication of further studies on more patients, together with the results of a longer follow-up period will contribute to the creation of national data.

In conclusion, it is pleasing that these two drugs, which have been brought into use after having been approved for the indication of IPF, give us the hope that something can be done for the medical treatment of IPF. Our part is to share our treatment and follow-up results in the appropriate scientific environments.

\section{REFERENCES}

1. Travis WD, Costabel U, Hansell DM, King TE Jr, Lynch DA, Nicholson AG, et al. An Official American Thoracic Society/European Respiratory Society Statement: Update of the International Multidisciplinary Classification of the Idiopathic Interstitial Pneumonias. Am J Respir Crit Care Med 2013; 188: 733-48. [CrossRef]

2. Raghu G, Collard HR, Egan JJ, Martinez FJ, Behr J, Brown KK, et al. ATS/ ERS/JRS/ALAT Committee on Idiopathic Pulmonary Fibrosis. An official ATS/ERS/JRS/ALAT statement: idiopathic pulmonary fibrosis: evidence-based guidelines for diagnosis and management. Am J Respir Crit Care Med 2011; 183: 788-824. [CrossRef]

3. King TE Jr, Bradford WZ, Castro-Bernardini S, Fagan EA, Glaspole I, Glassberg MK, et al. A phase 3 trial of pirfenidone in patients with idiopathic pulmonary fibrosis. N Engl J Med 2014; 370: 2083-92. [CrossRef]

4. Noble PW, Albera C, Bradford WZ, Costabel U, Glassberg MK, Kardatske D, et al. Pirfenidone in patients with idiopathic pulmonary fibrosis (CAPACITY): two randomised trials. Lancet 2011; 377: 1760-9. [CrossRef]

5. Richeldi L, du Bois RM, Raghu G, Azuma A, Brown KK, Costabel U, et al. Efficacy and safety of nintedanib in idiopathic pulmonary fibrosis. N Engl J Med 2014; 370: 2071-82. [CrossRef]

6. Richeldi L, Cottin V, du Bois RM, Selman M, Kimura T, Bailes Z, et al. Nintedanib in patients with idiopathic pulmonary fibrosis: Combined evidence from the TOMORROW and INPULSIS ${ }^{\circledR}$ trials. Respir Med 2016 Feb 3. doi: 10.1016/j.rmed.2016.02.001 [Epub ahead of print] [CrossRef]

7. Kreuter M, Bonella F, Wijsenbeek M, Maher TM, Spagnolo P. Pharmacological Treatment of Idiopathic Pulmonary Fibrosis: Current Approaches, Unsolved Issues, and Future Perspectives. Biomed Res Int 2015; 2015: 329481. [CrossRef]

8. Akıncı Özyürek B, Erdoğan Y, Yılmaz Demirci N, Büyükyaylacı Özden S, Özdemirel Şahin T. Our experience with pirfenidone in patients with idiopathic pulmonary fibrosis. Eurasian J Pulmonol 2016; 18: 61-2. 